Journal of Social Sciences 2 (1): 1-6, 2006

ISSN 1553-345X

(C) 2006 Science Publications

\title{
Educational Attainment of Jordan's Population and Labor Force
}

\author{
Mwafaq Dandan Al-Khaldi \\ Amman University College for Financial and Administrative Sciences \\ AL- Balqa Applied University, P.O. Box 1705, Amman, Jordan
}

\begin{abstract}
The analysis of the educational attainment by Gender tells us about the general demand for education and qualitative change both in population and labor force. The term educational attainment used here refers to the actual level of education completed by a person as it is superior to the enrolment ratio - as a proxy for educational attainment - especially for the measurement of the stock of human capital. The study aims at exploring the educational characteristics of population by gender, as compare with that of labor force during the past three decades. Also the study aims at exploring the educational status of female population and labor force and will finding out whether this status has improved or worsened. The study attempts to find out the relation between the educational level of population and the participation rate in the labor force. To achieve the above aims the study employs the descriptive and the analytical statistical methods through some quantitative comparisons for the characteristics of population and labor force .From the analysis of the related data the study revealed an increasing demand for education not in terms of educational enrollment but in terms of actual educational attainment. The study also found that the labor force is much better educated than population while the analysis of educational attainment by gender indicated that the improvement was in favor of female population and labor force.
\end{abstract}

Key words: Population, labor force, education

\section{INTRODUCTION}

Many of the great economists have long been aware of human resource development. Adam Smith, who was a moral philosopher as well as an economist, stressed the importance of education at various points in the "wealth of nations" He viewed education as a kind of capital, which embodies acquired knowledge and skills. He noted that Scotland of his days had superior intelligence and her people had providential and orderly habits due to the national system of education ${ }^{[1]}$.

J.S.Mill advocated public education as he wrote "it inculcates habits of prudence economy and selfimprovement which is carried further for the purpose, therefore of altering the habits of the laboring people and effective national education of the children of laboring class is the first thing needful ${ }^{[2]}$.

Alfred Marshall developed the educational ideas of Adam smith by describing education as " a National Investment ", Marshall advocated the education of the working class and favored technical education. He emphasized the impact of the family, especially of women on the betterment of children's environment and intelligence claiming that, "The most valuable at all capital is that invested in human beings" Karl Marx was agitated over the inhuman results of the division of labor and the exploitation of the working class. He pointed out that" when the working class comes into power, as invariably it must give, technical instruction both theoretical and practical would take its proper place in the working class school ${ }^{[3]}$.

Some modern economists virtually ignored the human resources factors in economic development, but by the 1960's human resources especially education had become economically interesting. Though education contributes directly to economic growth it is also necessary for the transformation of social and political institutions which peoples of modern nations are seeking. This objective cannot be divorced from that of economic growth in any realistic analysis leading to policy prescriptions.

Jordan plans do show the basic awareness of the important of education in securing rapid growth. Jordan economy already is moving towards a service emphasis in 2001 about $42.2 \%$ of GNP came from exports. This production comes increasingly from services. Nearly $80 \%$ of Jordan GDP derives from services as opposed to more traditional production. In real terms, the growth of service production has outpaced the growth of total GDP during the year's between1990-2000. But an economy where services play a key role is an economy where education is the raw material ${ }^{[4]}$.

By 1970 Jordan launched a program to create a resource - human capital. Since that time education has expanded rapidly. The educational statistics of Jordan show a remarkable improvement in school enrollment

Corresponding Author: Dr. Mwafaq Dandan Al-Khaldi, Amman University College for Financial and Administrative sciences, AL- Balqa Applied University, P.O. Box 1705, Amman, Jordan, Tel: 0096265346183 , Mob: 00962777487979 
ratio among the younger population aged (6-24) years. The age group of (6-16) years, which correspond with the basic education system, has reached $94.6 \%$ in 1995. The enrollment ratio for male population of this age group, has moved up from $80.4 \%$ in 1970 to $94.25 \%$ in 1995 while that of female population of the same age group has reached $94.98 \%$ in 1995 from $68.7 \%$ in 1970 showing an increase of $26.28 \%$ pointes over the period 1970 to 1995 compared to $13.85 \%$ pointes an increase in male enrollment ratio over the same period. The secondary education is the second stage of the educational system in Jordan, corresponding to the age group 17 and 18 years. The enrollment ratio for this age group was $27.54 \%$ in 1970 increasing to $69.9 \%$ in 1995 which gives an increase of more than $46.36 \%$ pointes. The male and female students enrolled at the secondary education accounted for $37.77 \%$ and $16.56 \%$ of their age groups respectively in 1970 .However; these figures went in 1995 up to $67 \%$ and $72.22 \%$ respectively. It is clear form these figures that female enrollment ratio has improved much faster than that of male population for this stage of education. On the other hand the enrollment for higher education corresponding with the age group 19-23 yeas has improved from $2.6 \%$ in 1970 to $26.6 \%$ in $1990^{[5]}$.

From the above figures, it is observed that the educational system has been expanding rapidly. The educational statistics with respect to enrollment ratios show that male population has enjoyed a higher enrollment ratio than female population of the same age groups during the 1970 `s and early 198`s.However, the increase in the enrollment ratios at different levels of education was mainly due to the parents awareness towards education and the implementation of government policy, this increase also can be taken to show the efficiency of the educational system of Jordan in providing the educational opportunity and meeting the increased demand for education of different age groups $^{[6]}$.

\section{MATERIALS AND METHODS}

This study attempts to analyze the educational attainment of Jordan's population and labor force by gender, utilizing different descriptive statistical technique- such as ratio, tables and co-efficients.

The comparison of the educational attainment of population and labor force by gender is examined through the use of co-efficient of equality by gender.

i.e .The total female population of each educational level. / The total male population of each educational level

Sources of data: The study is based on the following sources of data:

1. Households Survey of 1961, 1974, 1979 and 1994, Department of Statistic.
2. Labor and Employment Surveys of 1992-2002 Departments of Statistics.

3. Employment and Unemployment Survey, Department of statistics, 2004

4. The Educational Yearbooks, Ministry of Education.

5. The Annual Reports of the Ministry of Higher Education.

Objectives of the study: This study aims to find out:

1. The actual level of educational attainment of the Jordanian population that was achieved during the past three decades.

2. The educational attainment of the Jordanian labor forces in Jordan and compare it with that of the population.

3. The educational level of the population and its effect on the participation rate in the labor force.

4. This study will also find out the actual status of female population in terms of educational attainment and compare it with the status of male population.

Educational attainment of population: With the increase in school attendance among the younger population, the literacy rate among the adult population (above 15 years of age) improved a great deal during the period of 1961 to 1999 as it is shown in Table 1.

The literacy rate in 1961 was only one third of the population - which was higher than many other Arab countries at the same time. This rate improved to 61.8 and $66.5 \%$ in 1974 and 1979 respectively, and went up to $85.73 \%$ in 1994 while in 1999 it has reached to $86.94 \%$.

The literacy rate among the age group (15-19) years was the highest among the population for all the years. In 1961 it was $54.7 \%$ and went up to $88.4 \%$, $93.5 \%$ and $98.24 \%$ in 1974,1979 and 1999 respectively, whereas the literacy rate for the age group (20-24) years was $40 \%$ in 1961, it increased to $80.6 \%$, $86.9 \%$ and 97.7 in 1974,1979 and 1999 respectively. The lowest literacy rate is among the age group (50 years) which was $12.4 \%$ in 1961 then improved to $51.1 \%$ in 1999 . Table 2 shows the educational attainment of population given in the population

Censuses of Jordan for the years, 1979, 1994 and 2004 which shows the following:

Population with formal education (excluding literate population) as a proportion of the total population of $52.05 \%$ in 1979 went up to $78.75 \%$ in 1994 and $85.3 \%$ in 2004. In absolute term the population with formal educational attainment went up from 505579 in 1979 to 2872006 in 2004 which gives an increase of 4.68 times during the period of 19792004.

As against this, the proportion of literate population (who can read and write only) has fallen down from $14.48 \%$ in 1979 to $6.98 \%$ in 1994 and $4.4 \%$ 
Table 1: Literacy Rate of Jordan's population by age group

\begin{tabular}{llllll}
\hline AGE GROUP & 1961 & 1974 & 1979 & 1994 & 1999 \\
\hline $15-19$ & 54.7 & 88.4 & 93.5 & 96.10 & 98.24 \\
$20-24$ & 40.0 & 80.6 & 86.9 & 96.2 & 97.7 \\
$25-29$ & 43.2 & 71.7 & 78.0 & 95.25 & 96.85 \\
$30-39$ & 30.6 & 52.0 & 36.5 & 91.23 & 93.88 \\
$40-49$ & 22.4 & 46.6 & 44.9 & 47.2 & 83.05 \\
50 years and above & 12.4 & 28.9 & 31.0 & 87.81 & 51.5 \\
Grand total & 32.4 & 61.8 & 66.5 & 85.73 & 86.94 \\
\hline
\end{tabular}

Source: Population Censuses for the relevant years, Department of Statistics Government of Jordan.

Table 2: Educational attainment of population by gender and educational level (15 years and above)

\begin{tabular}{|c|c|c|c|c|c|c|c|c|c|c|c|c|}
\hline \multirow{2}{*}{$\begin{array}{l}\text { Educational } \\
\text { level }\end{array}$} & \multicolumn{3}{|l|}{1979} & \multicolumn{3}{|l|}{1994} & \multicolumn{3}{|l|}{2004} & \multicolumn{3}{|c|}{ Coefficient of education } \\
\hline & total & male & female & total & male & Female & total & male & female & 1979 & 1994 & 2004 \\
\hline Illiterate & 325106 & 92336 & 232770 & 306220 & 83865 & 222355 & 344162 & 96674 & 247488 & 2.52 & 2.65 & 2.56 \\
\hline$\%$ & 33.47 & 18.88 & 48.25 & 14.27 & 7.74 & 20.93 & 10.3 & 5.6 & 15.1 & & & \\
\hline Literate & 140690 & 88818 & 51872 & 149686 & 84417 & 65269 & 148487 & 81137 & 67350 & 0.58 & 0.77 & 0.83 \\
\hline$\%$ & 14.48 & 18.16 & 10.75 & 6.98 & 7.8 & 6.14 & 4.4 & 4.7 & 4.1 & & & \\
\hline Elementary & 192437 & 163016 & 29421 & 345564 & 190583 & 154981 & 423767 & 243411 & 180356 & 0.70 & 0.81 & 0.74 \\
\hline$\%$ & 19.81 & 23.11 & 16.46 & 16.10 & 17.61 & 14.58 & 12.6 & 14.1 & 11.0 & & & \\
\hline Preparatory & 170302 & 101236 & 69066 & 609526 & 330280 & 279246 & 1267423 & 687076 & 580347 & 0.68 & 0.85 & 0.84 \\
\hline$\%$ & 17.53 & 20.70 & 14.32 & 28.41 & 30.5 & 26.28 & 37.6 & 39.8 & 35.7 & & & \\
\hline secondary & 86077 & 53906 & 32171 & 379054 & 196362 & 182692 & 594136 & 305558 & 288578 & 0.59 & 0.93 & 0.94 \\
\hline$\%$ & 8.86 & 11.03 & 6.67 & 17.67 & 18.13 & 17.2 & 17.7 & 17.7 & 17.6 & & & \\
\hline Diploma & 28464 & 16304 & 12160 & 200886 & 89468 & 111418 & 268255 & 113937 & 154318 & 0.75 & 1.24 & 1.35 \\
\hline$\%$ & 2.93 & 3.33 & 2.52 & 9.36 & 8.26 & 10.48 & 8.0 & 6.6 & 9.4 & & & \\
\hline $\mathrm{BA}+$ & 28299 & 23353 & 4946 & 154668 & 107899 & 46769 & 318425 & 198527 & 119898 & 021 & 0.43 & 0.60 \\
\hline$\%$ & 2.91 & 4.79 & 1.03 & 7.21 & 9.93 & 4.39 & 9.4 & 11.5 & 7.31 & & & \\
\hline total & 971375 & 538969 & 432406 & 2145604 & 1082874 & 1062730 & 3364655 & 1726320 & 1638335 & 1979 & 1994 & 2004 \\
\hline$\%$ & 100 & 100 & 100 & 100 & 100 & 100 & 100 & 100 & 100 & 2.52 & 2.65 & 2.56 \\
\hline $\begin{array}{l}\text { Population } \\
\text { with formal } \\
\text { education }\end{array}$ & 505579 & 357815 & 147764 & 1689698 & 914592 & 775106 & 2872006 & 1548509 & 1323497 & & & \\
\hline$\%$ & 52.05 & 62.96 & 41 & 78.75 & 84.46 & 72.93 & 85.3 & 89.7 & 80.8 & & & \\
\hline
\end{tabular}

Sources: Dep. of Statistics, Government of Jordan

1. Multi Purposes Housing and Population Survey 1979

2. Accompanying Survey of Population and Housing Survey 1994

3. Employment and Unemployment Survey 2004

Table 3: Educational Attainment of Jordan's Labor Force by Gender and Educational Level (Percentages only)

\begin{tabular}{|c|c|c|c|c|c|c|c|c|c|c|c|c|}
\hline \multirow[t]{2}{*}{ Educational level } & \multicolumn{2}{|l|}{1979} & \multicolumn{3}{|c|}{1994} & \multicolumn{3}{|c|}{2004} & \multicolumn{4}{|c|}{ Coefficient of education } \\
\hline & Total & Male & Female & Total & Male & Female & Total & Male & Female & 1979 & 1994 & 2004 \\
\hline Illiterate & 18.46 & 19.4 & 6.74 & 8.00 & 8.62 & 4.61 & 2.8 & 2.9 & 2.14 & 0.028 & 0.098 & 0.117 \\
\hline Literate & 20.95 & 22.39 & 3.11 & 8.97 & 9.94 & 3.63 & 3.4 & 3.8 & 0.8 & 0.011 & 0.067 & 0.03 \\
\hline Elementary & 23.61 & 25.07 & 5.43 & 17.51 & 19.47 & 6.78 & 12.1 & 13.7 & 2.02 & 0.017 & 0.064 & 0.02 \\
\hline Preparatory & 12.29 & 12.65 & 7.72 & 22.58 & 24.38 & 12.75 & 35.9 & 39.7 & 12.61 & 0.049 & 0.096 & 0.05 \\
\hline Secondary & 10.99 & 9.72 & 26.88 & 15.36 & 15.29 & 15.78 & 14.9 & 15.4 & 12.8 & 0.22 & 0.19 & 0.12 \\
\hline M. Diploma & 6.87 & 4.44 & 37.04 & 14.85 & 10.65 & 37.76 & 11.6 & 9.1 & 27.53 & 0.67 & 0.65 & 0.48 \\
\hline $\mathrm{BA}+$ & 6.83 & 6.33 & 13.08 & 12.73 & 11.65 & 18.69 & 19.3 & 15.4 & 43.1 & 0.16 & 0.28 & 0.44 \\
\hline Total & 100 & 100 & 10 & 100 & 100 & 100 & 100 & 100 & 100 & - & - & - \\
\hline $\begin{array}{l}\text { Labor force with } \\
\text { formal education }\end{array}$ & 60.59 & 58.21 & 90.15 & 83.03 & 81.44 & 91.76 & 93.8 & 93.3 & 97.06 & - & - & - \\
\hline
\end{tabular}

Sources: Dep. of Statistics, Government of Jordan

1-Multi Purposes Housing and Population Survey 1979

2-Accompanying Survey of Population and Housing Survey 1994

3-Employment and Unemployment Survey 2004

in 2004 which was lower than the proportion of the population with formal education.

The proportion of population with elementary level of educational attainment was $19.81 \%$ in 1979 , which fell to $16.10 \%$ in 1994 and $12.6 \%$ in 2004 . While the proportion of population with preparatory educational attainment has moved from $17.53 \%$ in 1979 to $28.41 \%$ in 1994 while in 2004 it has reached to $37.6 \%$.

In $1979,8.86 \%$ of the total population had secondary education and then this proportion increased to $17.7 \%$ in 2004 . This means that it has increased by $8.84 \%$. In absolute terms, it has increased from 86077 in 1979 to 594136 in 2004 or by 5.9 times. The proportion of population with middle diploma level of education in 1979 was $2.93 \%$, while in 2004 it reached $8 \%$ in 2004 and. In absolute term it has increased by more than 8.4 times, i.e. it was 28464 in 1979 and increased to 268255 in 2004.

Similarly, the proportion of degree level of educational attainment and above increased from $2.91 \%$ 
in 1979 to $7.21 \%$ in 1994 and $9.4 \%$ in 2004 , whereas in absolute term it has increased by 11 times from 28299 in 1979 to 318425 in 2004.

It is clear that the growth rate of educational attainment of Jordan's population is very fast especially for the level of higher education, which is but natural in view of the well known fact of the top heavy structure of Jordan's formal educational system.

Educational attainment of population by gender: In Table 2, the educational attainment of population by gender is also given which shows the following:

The proportion of illiterate females in the total population is higher than that of illiterate males. The trend in this regard as revealed by 1979, 19942004 censuses is interesting. In $1979,48.25 \%$ of the female population was illiterate as against $18.88 \%$ of the male population giving the variation of $29.37 \%$ gender wise.

After 25 years of development the incidence of illiteracy by gender has decreased i.e. the difference in their illiteracy rate has decreased by $19.87 \%$ points i.e. from 29.37 in 1979 to $13.19 \%$ in 1994 , and to 9.5 points in 2004, the relative position of females has improved The co-efficient of illiteracy also confirms the above observation. In 1979, it was 2.52 and 2.56 in 2004.This means that against one illiterate male there were 2.52 illiterate females in 1979 and 2.56 in 2004. The literacy co-efficient computed for this purpose suggests that it has improved in favor of females. The co-efficient for the two census years i.e. 1979 and 2004 were 0.58 and 0.83 respectively. This shows that against one literate male there were 0.58 literate females in 1979 and 0.83 in 2004. The co-efficient similarly worked out for the elementary level of education also lead us to the same conclusion, the respective co-efficient are 0.70 and 0.74 indicating relative improvement in the status of females over the time. For preparatory level of education, the values of co-efficient of 0.68 and 0.84 for the years 1979 and 2004 respectively show educational level by gender.

The co-efficient for secondary level of education for the years 1979 and 1994 and 2004 were $0.59,0.93$ and .94 respectively, whereas the co-efficient for middle diploma shows a great deal of improvement in the female status on this level of education which increased from 0.75 in 1979 to 1.24 in 1994 and to 1.35 in 2004. This indicates that the growth rate of female educational attainment on this level was higher than that of male which are due to higher female attendance at this level of education and that is because of social and economic factors. The co-efficient for the first university degree level of education and above for the years 1979, 1994 and 2004 were 0.21 and 0.43 and0.60 respectively. The number of male population with middle diploma level of educational attainment was 16304 in 1979 and increased to 113937 in 2004, we can say that when the male population on this level increased by 5.98 times from 1979 to 1994, the female population at the same level of education increased by 11.7 times during the same period.

The male population with university degree level of educational attainment and above was 4.72 times more than that of females in 1979 , came down to 2.3 in 1994 and 1.65 in 2004.

Educational attainment of the labor force: Before going to the educational attainment of the labor force, we shall look at two of the major characteristics of Jordan's labor force.

These two characteristics are the low labor-force participation rate and extremely low contribution of women to the labor force ${ }^{[7]}$. When the economically active population enumerated in the 1961 census is compared with the equivalent data given in 1979 census, the gross labor participation rate declined from $24.2 \%$ in 1961 to $21.25 \%$ in 1979 and $23.3 \%$ in 1998 . One of the major factors for this decline is the higher dependency ratio caused by the increased fertility on one hand and by the accelerated out migration of the active younger male segments of population, on the other. Another factor is the rapid increase in school enrollment among the youthful population. As it is shown on the same censuses that the enrollment ratio among the population aged (6-24 years) reached $81.3 \%$ in 1998 compared to $34 \%$ in 1961 which reflected the decline in the labor participation rates for the age group (6-24 years).

The same censuses show that the gross labor participation rate of the female population appreciably increased from $1.9 \%$ in 1961 to $3.07 \%$ in 1979 and then it rose to $8 \%$ in 1998 . The rise in their participation rate is most pronounced among the age group of 20-24 years especially in urban areas. However, it must be pointed out that the female participation rate in Jordan's labor force still remains very low ${ }^{[8]}$.

Educational attainment is one of the most important factors which affect the participation in the labor force especially in case of female participation. The following table shows the educational attainment of the labor force given in 1979 and 1994 censuses and 2004 employment and unemployment survey.

According to the 2004 census, around $2.8 \%$ of Jordan's labor forces were illiterate. Thus, $97.2 \%$ of the labor forces were educated. If we take out the proportion of the literate labor force (can read \& write) which is around $3.4 \%$ from the total educated labor force, then $93.8 \%$ of the total labor force seems to have invested in education. This proportion of labor force with educational attainment has increased from $60.59 \%$ in 1979 to $83.03 \%$ in 1994 . Thus it has increased by more than $33.21 \%$ points during that period (1979 to 2004). This increase in the proportion of educated labor competes favorably with the growth of the proportion of educated population, which has increased by $33.25 \%$ points during the same period. 
The analysis of educational attainment of Jordan's labor force through levels of education further confirms the top-heavy character of the Jordanian educational system. The proportion of the labor force with elementary educational attainment was $23.61 \%$ in 1979 and decreased to $17.51 \%$ in 1994 and $12.1 \%$ in 2004 . This decrease in the proportion of the labor force with elementary level of education was reflected in the preparatory level of educational attainment, which increased from $12.29 \%$ in 1979 to $22.58 \%$ in 1994 while in 2004 it reached to $35.9 \%$, which means it has increased $23.61 \%$ points.

Similarly, the proportion of the labor force with secondary level of education has increased by almost $4 \%$ points (from $10.99 \%$ in 1979 to $14.9 \%$ in 2004). Unlike this, the growth of educational attainment for middle diploma and degree level of education is higher than what we have observed in the case of elementary, preparatory and secondary levels of education. The proportion of the labor force with middle diploma level of education in 2004 was almost two times of the same proportion of 1979 , the respective proportions were $11.6 \%$ and $6.87 \%$.

In $1979,6.83 \%$ was the proportion of the labor force with first university degree and above attainment; it then increased to $12.73 \%$ in 1994 and $19.3 \%$ in 2004. Thus if we take the last two levels of education (M. Diploma, University Degree and Higher Studies) together, we find that this proportion in 2004 was double the same proportion in 1979, i.e. in 1979 this proportion was $13.7 \%$, while in 2004 it moved up to $30.9 \%$. This indicates that the skilled level of Jordan's labor force has improved over the period of time.

Educational attainment of labor force by gender: The educational attainment of the labor force by gender has to be studied to get an idea of the educational distance between the male and female labor force. This may throw light on the formation of human capital through investment in education by gender.

Firstly, the proportion of illiterate male labor force was higher than the proportion of female illiterate labor force. The gender-wise gap of illiteracy that was $12.66 \%$ in 1979 decreased to $4.01 \%$ in 1994 and $0.1 \%$ in 2004 .

Thus, in comparison to females in Jordan's labor force, males are more illiterate, which is due to low participation rate of females in the labor force. If we take a look at the participation rates by educational level we find it is the lowest among illiterate females.

According to the 1979 census, the proportion of literate male labor force to total male labor force was $2139 \%$ and that of the females was $3.11 \%$, in comparison, the proportion of the male labor force with investment in formal schooling was $59.21 \%$ and that of the female labor force was 90.15\%. In 1994, the proportion of the male labor force with investment in formal education increased to $81.44 \%$ and that of females remained almost the same at $91.76 \%$.The corresponding proportion for male and female literate labor were 9.94 and $3.63 \%$ respectively in 1994 while in 2004 the proportion of male labor force with investment in education was $93.3 \%$ and that of females was $97.06 \%$.

Similarly in 2004, 2.9\% was the proportion of illiterate male labor force and $2.14 \%$ was the proportion of the illiterate female labor force. As noted earlier, as against $97.06 \%$ educated female labor force there were $93.3 \%$ educated male laborers. The former proportion was more $30.94 \%$ points more than the latter in 1979 and in 2004 the proportion of educated female labor force was more than that of male by $3.76 \%$ points. This reflects the narrowing of educational distance by gender.

In absolute terms, the total male labor force was 12 times that of the total female labor force in 1979 and 5.5 times in 1994, while the educated male labor force was 7.84 times of the educated female labor force in 1979 and 5.6 times in 1994.

The observed narrowing of educational level in terms of year of schooling between the genders may not necessarily reflect the reduction in equality of investment in education for the same level of educational attainment (in terms of years of schooling), an average male spends more on his education than the female. The quality of human capital in the two is bound to be different. This issue is relevant in the case of increasing the proportion of female labor participation in the productive activities. Even if a small proportion of educated female labor force is engaged in productive activities, their contribution to non-market (household) production should not be ignored. From this stand point, the narrowing of educational level between male and female labor force is important. Narrowing of educational level between male and female labor force may also be studied by estimating the coefficient of educational equality. For the literate labor force by gender, the value has changed from 0.011 in 1979 to 0.067 in 1994 and 0.03 in 2004 . Similarly, at the elementary level of education, the value of co-efficient changed from 0.017 to 1979 to 0.064 in 1994 and 0.02 in 2004. For the preparatory level, it was 0.049 and 0.096 in 1979 and 1994 respectively, then going down to $0.05 \mathrm{in} 2004$

The value of co-efficient for secondary education was $0.22,0.19$ and 0.12 in 1979, 1994 and 2004 respectively. The highest value co-efficient was for middle diploma level of education which changed from 0.67 in1979 to 0.48 in 2004. Similarly for degree level of education and above it was $0.16,0.28$ and 0.44 in 1979, 1994 and 2004.

These improvements on the values of co-efficient indicate the spread of education among Jordan's labor force especially at the higher levels of education. 


\section{CONCLUSION}

The main conclusions of the analysis of educational attainment of Jordan's population and labor force by gender and level of education are outlined below:

1. From the analysis of the educational attainment in Jordan, it was noticed that there is an increasing demand for education not in term of educational enrollment but in terms of actual educational attainment where the proportion of literate population to total population during the period of 1979-2004 has declined, whereas the proportion of educated population to the total has increased. This can be taken as an evidence of increasing the proportion of population with formal schooling. It was also seen that the proportion of educated population to total population has increased much faster at the higher level of education (secondary and above) than that at the elementary and preparatory levels of education. The stock of educated persons (with formal education only) has gone up from $52.05 \%$ in 1979 to $78.75 \%$ in 1994 and $85.3 \%$ in 2004 . From this observation, it is clear that the increase in the stock of educated persons implies a corresponding increase in the supply of skill in Jordan's economy.

2. The ratio of educated male to female at various levels of education has improved over the time. In 1979, for example against one male with preparatory educational attainment there was 0.68 female with the same level of education; this ratio has improved to 0.84 in 2004 . For the middle diploma, also the ratio has improved from 0.75 in 1979 to 1.35 in 2004, In other words the educational attainment by gender reveals that there is a tendency towards narrowing of educational gap between male and female population.

3. The proportion of educated labor force to total labor force was higher than the percentage of educated population to the total population, the former was $93.8 \%$ of the total labor force whereas the latter was $85.3 \%$ of the total population in 2004 .The educational attainment of the labor force by gender reveals that the proportion of educated female labor force to the total female labor force was higher than that of male labor force .In 1979 the proportion of educated female labor force to the total was $93.26 \%$ and went up to $97.86 \%$ in 2004 , while that of male labor force has improved from $80.6 \%$ in 1979 to $97.1 \%$ in 2004 . In other words the educational attainment of labor force indicate that the female labor force enjoyed a much better educational attainment than male labor force in Jordan during the period 1979 -2004

4. The proportion of the labor force with professional educational attainment (Middle Diploma \& above) has increased in absolute number by $216 \%$ from
1979 to 1994 , which has exceeded the growth rate of the total labor force of $115.8 \%$ over the same period. This indicates an increasing demand for the skilled labor in Jordan as that proportion to the total labor force has gone up from $13.7 \%$ in 1979 to $27.58 \%$ in 1994 and $30.9 \%$ in 2004 which indicates that there is an improvement in the skilled level of Jordan's labor force.

5. The study also found that with the improvement of the general education level of the total population, the participation rate has improved for middle diploma holders and above

\section{SUGGESTIONS}

1. Educational expenditures should be increased in order to open more schools especially in rural areas

2. Though the literacy rate has reached almost $90 \%$ of the total population - which is much higher many other Arab countries- but it is still considered to be low with a country has reached to a nearly full enrollment ratios by the end of 1970s. This indicates that the educational system suffers from a high drop out ratios. So an effective measures should be taken to improve the internal efficiency of educational system i.e. reduction in drop out ratio.

\section{REFERENCES}

1. Blaug Mark(Ed), (1970) Introduction to Economics of Education, Allen Lane, the Penguin Press, London

2. J.S Mill, The Principles of Political Economy, London 1876 p.p.263 (book -8 II chapter XIII)

3. Fredrick H. And Charles Myers, (1964) Education, Man Power and Economic Development, Mc Craw Hill Series in International Development

4. Mousa S. alozi (2001) Human Resources in Jordan-Policies, Planning and expenditures, Alyagdah publications, Amman Jordan

5. Hashemite kingdom of Jordan, Ministry of Education, Report on Education in Jordan for the 21st Century, Dec. 1992.

6. Hashemite kingdom of Jordan, Ministry of Education, Progress of Education in Jordan (198183). A report submitted to the 39 th session of the International Conference on Education, Geneva, 1984

7. Hashemite kingdom of Jordan, Department of Statistics, Population Censuses of 1961, 1974, 1979and1994.

8. Fathi Nsour, Educational Characteristics based on the 1979 Housing and Population census (Arabic ) a research paper was presented on the symposium on population, fertility and Family Health in Jordan, 28.-30, Aug, 1984, Dept. of Statistics, Govt. of Jordan. 